\title{
Developing a GIS-based inventory of South Africa's public libraries: The Public and Community Libraries Inventory of South Africa (PaCLISA) project
}

\author{
Peter Johan Lor' \\ Department of Information Science, University of Pretoria \\ peter.lor@ifla.nl \\ Paul van Helden ${ }^{2}$ \\ Centre for Geoinformation Science, University of Pretoria \\ paul.vanhelden@up.ac.za \\ Theo J D Bothma ${ }^{3}$ \\ Department of Information Science, University of Pretoria \\ theo.bothma@up.ac.za
}

\begin{abstract}
Received: / I th June 2005
Accepted: $13^{\text {th }}$ September 2005

During 2000-2004 a project was undertaken to create a comprehensive and informative inventory of South African public and community libraries, the Public and Community Libraries Inventory of South Africa (PaCLISA). The project was executed in two phases, initially under the guidance of the Libraries Working Group of the Print Industries Cluster Council (PICC). Phase I was carried out during 2000-200I and funded by The Carnegie Corporation of New York and the Foundation for Library and Information Service Development (FLISD), through the National Library of South Africa. The Centre for Geo-Information Science of the University of Pretoria was contracted to carry out the project. In light of the response to Phase I, a consultative process was followed to redesign the inventory questionnaire, after which Phase 2 was carried out during 2003-2004 as a project of the Department of Information Science and the Centre for Geo-Information Science of the University of Pretoria. Although the project was not an unqualified success, it was a valuable learning experience. The article provides an overview of the project with special emphasis on the lessons that have been learned and what these imply for future efforts to inventorise South Africa's public libraries.
\end{abstract}

Key Words: PaCLISA, public and community libraries in South Africa, GIS-based inventory

\section{Introduction}

South Africa's public libraries face huge challenges. Although South Africa is probably better endowed with public libraries than any other sub-Saharan country, the distribution and impact of these libraries have been skewed by the inequalities of the apartheid system. While affluent, largely white suburbs were well-served by branch libraries of urban and provincial public library systems, library provision in the black townships, informal settlements and rural communities left much to be desired. During the 1980 s the rise of community resource centres, established and maintained by non-governmental and community-based organisations, spearheaded a rethinking of the role of the public library in the community. It was clear to the committed that libraries are not value free or ideologically neutral. In the struggle against apartheid, community resource centres were part of the struggle (Stillwell, 1994, 1997; Mostert ,1998, 1999, Mostert \& Vermeulen, 1998, Leach, Stillwell and Verbeek, 1994).

With the coming of democracy in 1994, foreign donors diverted funding to the now legitimate government. Foreign funding for community-based organisations declined dramatically (Lor, 1998, Stillwell, 1997; Leach, Stillwell and Verbeek, 1994). As a result many community resource centres were closed down or merged with local public libraries. Managers of the latter, in an attempt to realign their institutions, started renaming their agencies community libraries. Where township residents tended to look upon public libraries with suspicion as agencies of the discredited municipal structures of the apartheid government, the term "community library" was intended to imply a non-elitist library of, by and for the community. In practice, the difference between the agencies called "public" and "community libraries" is today largely one of emphasis, if not packaging. In this article the terms are considered to be essentially synonymous.

I. Peter Lor, is IFLA Secretary General and Extraordinary Professor, Department of Information Science, University of Pretoria, South Africa.

2. Paul van Helden is Associate Professor and Director of the Centre for Geoinformation Science, Department of Geography, Geoinformatics and Meteorology, University of Pretoria, South Africa.

3. Theo Bothma is Professor and Head of the Department of Information Science, University of Pretoria, South Africa. 
Economic realities and many urgent needs competing for the same funds meant that the coming of an ANC-led government in 1994 did not automatically translate into a significant investment in public libraries (Brown, 2004). A largescale and still ongoing reorganisation of local and provincial government created much uncertainty. Management, funding and morale were affected (Mametse, 2003; Baker 2004; Anderson 2005). Today the public library scene in South Africa is difficult to summarise. There are areas of neglect and pockets of excellence. New buildings may be erected in formerly disadvantaged communities, but there may be no money to stock them, or existing libraries may be starved of new materials while resources are diverted. South Africa has vast rural areas largely devoid of library service points (Mokgaboki, 2002) but, in contrast, also the prize-winning Smart Cape access project (Valentine 2004). Various government agencies pump capital into glamorous but technology-driven community IT projects such as telecentres. Many of these fail to thrive (Snyman \& Snyman, 2003), prompting the thought that the money could have been better spent on developing the IT infrastructure of the existing community libraries. Questions and doubts of this sort underline the need for rational, well-informed planning, which calls for reliable information.

Comparative statistics of South Africa's public libraries were included in the South African municipal yearbook for many years; in its successors (the Official South African Local Government Yearbook and Gaffney's Local Government in South Africa (e.g. 2004)) very limited or no library statistics are provided. Since South Africa's transition to democracy in the 1990s useful and reliable statistical data on the South African public and community libraries is not readily available. Wehmeyer (1995, 1996) compiled comparative statistics on the provincial library services, with the emphasis on the Western Cape Province. Hooper and Hooper's (2000) contribution to Issak's report, Public libraries in Africa, was based essentially in earlier reports by Lor (1998) and Leach (1998). Neither of these provides comprehensive statistics. Yet it is essential to keep and regularly update contextualised data in order to be able to successfully provide library services to the community and to effectively manage these services (Roux, Weich \& Fouché, 1986; Ramogale \& Fortuin, 2004, Iflanet, 2000).

Therefore, in 2000, when the Print Industries Cluster Council (PICC) and the National Library of South Africa expressed a need for a comprehensive and informative inventory of South African public/community libraries, the Public and Community Libraries Inventory of South Africa (PaCLISA) was commissioned. The project was executed in two phases, initially under the guidance of the Libraries Working Group of the PICC. Phase I was carried out during 2000$200 \mathrm{I}$ and funded by The Carnegie Corporation of New York and the Foundation for Library and Information Service Development (FLISD). Phase 2 was carried out during 2003-2004 as a low-budget self-funded project of the Department of Information Science and the Centre for Geo-Information Science of the University of Pretoria.

Although the project was not an unqualified success, it was a valuable learning experience. The purpose of this article is to provide an overview of the project with special emphasis on the lessons that have been learned and what these imply for future efforts to inventorise South Africa's public libraries.

\section{Goal and objectives of the project}

As its name indicates, the PaCLISA project was aimed at creating an inventory. This term was deliberately chosen, as distinct from a survey, because it aimed to provide a planning tool that would show what public and community library service points were in existence where. The term inventory further implies the creation of a tool that is kept up to date, rather than a once-off description. Plotting the physical location and hence spatial distribution of public and community libraries in a geographic information system (GIS) was a key dimension of the project. Researchers in the GeoLib Program at Florida State University had already alerted the library profession to the value of GIS systems in decision making about the location of public library service points (Koontz \& Jue, 2000, 200I). Their work led to the creation of the Public Library Geographic Database (PLGDB), launched in May 200I, which covers all of the United States (Jue \& Koontz, 2002a, 2002b; Koontz et al., 2004). However, at the time that the first phase of the PaCLISA project was launched in 2000, the experience gained in the United States was not yet available. PaCLISA was a pioneering effort, with little or no prior experience to go on.

In addition to creating the GIS that details the physical locality and distribution of the libraries, PaCLISA also attempted to quantify major parameters descriptive of the libraries, including the size and composition of collections of library materials, expenditure on library materials (books and other materials by age groups, languages, formats, etc.), users and patterns of use (percentage of target population, demographic characteristics, circulation etc.). In this way PaCLISA aimed to provide an accurate and reliable picture of the shape and size of the library environment.

This overall goal translated into the following immediate objectives:

- to obtain reliable and current data about each library;

- to create a database containing the data about all the libraries;

- to map the location of all the libraries in geographical context; 
- to obtain demographic information of the areas served by the libraries;

- to obtain market information on book and print purchasing by libraries;

- to produce a directory of public/community libraries;

- to create an information system on public/community libraries in South Africa; and

- to disseminate the findings.

\section{Phase I}

The first phase of the inventory is described by Van Helden and Lor (2002a). It commenced in November 2000 with the establishment by the PICC's Libraries Working Group of a Project Management Committee (PMC) and a Project Reference Group (PRG). Although the project was originally scheduled for the period of I October 2000 until 3I March 200 I, various revisions to the grant proposal caused it to be approved only on 12 October 2000. It was then further delayed by the onset of the December-January summer holidays in South Africa and the resultant slow-down in the activities of most institutions.

First, the scope of the survey was set to include all public and community libraries in South Africa, including depots. The following categories of data that had to be obtained from individual libraries were then identified as relevant to the survey:

- Identification information

- Collection information

- Circulation information

- Operating costs

- Source(s) of funding

- Staff

- Public services

- Facilities

- General problems experienced

- Demographic data

- Geographic data

After the questionnaire was designed it was approved by the PMC and PRG and later distributed to the public and community libraries in February and March 200 I. In South Africa the vast majority of public and community libraries form part of either provincial or metropolitan public library systems. There are nine provincial library authorities, in the provinces of Eastern Cape, Free State, Gauteng, Kwazulu-Natal, Limpopo, Mpumalanga, Northern Cape, Northwest Province and Western Cape, and at the time of the project the same number of metropolitan library authorities: Buffalo City (East London), Cape Town, Ekurhuleni, Ethekwini (Durban), Johannesburg, Mangaung (Bloemfontein ), Msunduzi (Pietermaritzburg), Nelson Mandela (Port Elizabeth), and Tshwane (Pretoria). (Several of the names changed during the course of the project.). Certain of these authorities provided substantial assistance to the project by distributing the questionnaires centrally from their head offices, afterwards collecting the completed questionnaires and checking them before they were returned to the project office. The first completed questionnaires were received in April 200I. The initial response was poor, and subsequently the cut-off date for the submission of questionnaires was changed many times. By the end of June, only $65 \%$ of the questionnaires had been returned (a total of 817 responses from 1253 libraries).

It was found that the delays experienced in receiving the completed questionnaires were due in part to the fact that many of the library systems were busy preparing their grant proposals to the Carnegie Corporation and this was an activity that had been given priority. More significantly, however, a radical restructuring of municipal authorities was underway at this stage, and as many of the municipal boundaries changed, public and community libraries were redistributed and reassigned to new municipal areas. This of course caused many libraries to be renamed, and also disrupted their sources and flow of funding.

In order to capture the data provided by the received questionnaires, as well as demographic information obtained from the Municipal Demarcation Board, a GIS database and an MS Access database were created.

The geographic coordinates of the libraries were mapped on the GIS database as precisely as the location data permitted. Basic information on the existence and location of 1253 public and community libraries had been obtained from the respective provincial and metropolitan library authorities and existing lists. The coordinates of all these libraries were input, regardless of whether or not they responded to the inventory questionnaire. In smaller towns and villages, libraries could not be plotted to street level because street-level maps were not available, but libraries in larger towns and cities were plotted to street level whenever their precise addresses could be determined. In the case of some of the libraries which did not respond, exact physical addresses were not known, and these libraries could be plotted only to 
cases response rates of over $90 \%$ were achieved. The result of this patchy response was that it was not possible to analyse the data and present countrywide findings on the state of public and community libraries in South Africa. Instead, analysis will have to focus on a number of authorities for which good responses were received. Also, as in Phase I, the data reported in the questionnaires that were returned was in many cases incomplete, fragmentary or unreliable. Thus even in provinces and metros with good response rates, it is not possible to arrive at reliable and informative findings in respect of all the questions.

\section{Lessons learnt}

The outcome of Phase 2 was disappointing, but the exercise has some value if it leads to a better understanding of the problem. What explanations can be given for the unsatisfactory response?

- In spite of the care taken in redesigning the inventory questionnaire, it was too long and difficult to complete, and considerable ambiguity remained.

- The practices and terminology used by the various library authorities differ. This leads to different interpretations of the same terms.

- The reorganisation of local government referred to under Phase I was still ongoing in Phase 2. Thus, in a given province some public libraries previously affiliated to a provincial library system might be transferred to a metro, and vice versa. Changes in procedures and different ways of collecting statistics made it difficult for respondents to complete the questionnaires, particularly in cases where transfers took place during the reporting year.

- Arising from the previous point, there was a great deal of uncertainty concerning the relationships between "main" and "branch" libraries in many towns. In some cases a number of responding libraries all gave the same address, that presumably being the address of the "main" library. In many cases aggregated data were reported by groups of libraries.

- The participation of representatives of most of the library authorities in the process to redesign of the questionnaire, in many cases failed to ensure the hoped-for "buy-in". In these cases the interest and commitment of the workshop participants failed to filter down to the library managers at local level.

- The project failed to raise sufficient awareness of the project among public and community library leaders.

- As a result of problems arising from legislation relating to the respective responsibilities of provincial and municipal government and financial relations between them (Dominy 2002), library managers were preoccupied with grave threats to the survival of their libraries.

- In comparison with Phase I, Phase 2 project lacked the resources for ongoing and persistent follow up of nonrespondents and clarification of suspect data.

Despite the disappointing outcome, PaCLISA should not be abandoned. Instead, a third phase should be undertaken, in which the lessons learned in the first two phases can be applied. Here one thinks of methodological improvements, such as the use of a greatly abridged and simplified inventory questionnaire and a more focussed campaign to ensure a higher response rate country-wide. After this the inventory should be updated in an economical basis (for example by providing a facility for respondents to update their data themselves on a website). A key success factor will be support for the project at the national level. Here the National Council on Library and Information Services (NCLIS), which would be one of the main beneficiaries of high quality information on the state of public and community libraries, should play a major role in raising the relevant role-players' and decision-makers' awareness of the importance of management information for the planning and development of South Africa's public and community libraries, and in persuading the provincial and metropolitan authorities to participate fully in the regular updating of the inventory.

\section{Conclusion}

Although Phase 2 of the PaCLISA project was not successful in terms of its data collection, its original objectives are still relevant. South Africa's public and community libraries are at a crossroads. As access to information in digital formats becomes a precondition for participation in community, national and international cultural, economic and political activities, public and community libraries have the potential to play a key role establishing democracy and improving the quality of life of all South Africans. But if opportunities are not seized, public and community libraries could be bypassed by the political decision-makers. Up-to-date, accurate and nationally comparable data on the capacity and impact of the libraries are essential for library advocacy as well as for their efficient management. In the wider scheme of things. good quality information is needed to underpin national strategies for the development of public and community libraries as channels for the dissemination of books and other printed material, and thereby help to promote literacy and a culture of reading and learning and to prepare South Africans for participation in the global knowledge society.

\section{Acknowledgements}

Funding from the Carnegie Corporation of new york and the assistance of Lise-Marie Keyser and Alithia Diakatos in preparing this article are gratefully acknowledged. 


\section{References}

Anderson, E. 2005. Public libraries in a woeful state. LIASA-in-touch 6(2): 15.

Baker, K. 2004. The information divide: publishing and access issues. Innovation: appropriate librarianship and information work in South Africa (29):24-31.

Brown, N.E. 2004. The shift from apartheid to democracy: issues and impacts on public libraries in Cape Town, South Africa. Libri 54(3): 169-178.

De Jager, K. \& Nassimbeni, M. 2005. Towards measuring the performance of public libraries in South Africa. South African journal of libraries and information science 7I(I):39-50.

Dominy, G. 2002. The Conundrum of Community Libraries in Provinces. Unpublished paper delivered at the Library and Information Association of South Africa (LIASA) Conference in Port Elizabeth in October 2002.

Gaffney's Local Government in South Africa 2004 - 2006. 2004. Sandton: The Gaffney Group.

Hooper, A.S.C. \& Hooper, V. 2000. Public libraries and community information services in South Africa: a brief summary of the issues; in Issak, A. 2000. Public libraries in Africa: a report and annotated bibliography. Oxford: International Network for the Availability of Scientific Publications: 153-163.

Iflanet: International Federation of Library Associations and Institutions. 2000. Revision of IFLA's guidelines for public libraries. June 2000. [Online]. Available: http://www.ifla.org/VII/s8/proj/gpl.htm. Accessed 20 June 2005.

Jue, D.K., and Koontz, C.M. 2002a. User's Manual for the National Digital Base Map of Public Library Locations, Version I.0, presented to the National Center for Education Statistics, U.S. Department of Education, Washington, D.C., 26 pp.

Jue, D. K. and Koontz, C. M. 2002b. Final Report, National Public Library Mapping Project. National Center for Education Statistics (NCES) and National Commission on Library and Information Services (NCLIS). May 2002.

Koontz, C.M. 2002. Customer based marketing. [Online]. Available http://www.geolib.org/pdf/MLSGeoMarketSize.pdf. Accessed 22 May 2005.

Koontz, C.M. \& Jue, D.K. 2000. Use of new technologies for better library management: GIS (geographic information system software) and PDAs (personal digital data collectors). Unpublished paper 083-120-E, 66th IFLA Council and General Conference Jerusalem, Israel, 13-18 August, 2000. [Online]. Available http://www.ifla.org//V/ifla66/papers/083-/20e.htm. Accessed 22 May 2005.

Koontz, C.M. \& Jue, D.K. 200I. The location of your library building: why it is important, and how to do it, using GIS (geographic information system software). In: Bisbrouck, M.F. (ed.) Library buildings in a changing environment; proceedings of the eleventh seminar of the IFLA Section on Library Buildings and equipment, Shanghai, China, I4-18 August 1999; 14I-153.

Koontz, C.M., Jue, D.K., McClure, C.R., \& Bertot, J.C. 2004. Public Library Geographic Database: what can it do for you and your library? Public Libraries 43(2): 113 - 119.

Leach, A. 1998. An overview of the public library sector in South Africa post 1994. Innovation: appropriate librarianship and information work in South Africa (16):3-19.

Leach, A., Stillwell, C. \& Verbeek, J. 1994. The reading of black South Africans: a historical overview. African journal of library, archives and information science 4(I): I- 13 .

Lor, P.J. 1998. Memorandum on the state of libraries in South Africa, March 1998. LIASA letter 2(I):7-12.

Mametse, D. 2003. On the brink of collapse: municipalities are pulling the plug on public libraries. Mail \& guardian February 1420: 9.

Mokgaboki, S.N. 2002. Extending community library and information services to rural areas - the challenge that lies ahead. South African journal of libraries and information science 68(I):78-79.

Mostert, B.J. 1998. Community libraries: the concept and its application, with particular reference to a South African community library system. International information and library review 30(I):7I-85.

Mostert, B.J. 1999. Information provision services in South Africa: a comparitive study. Library management 20(I):19-26.

Mostert, B.J. \& Vermeulen, W.M. 1998. Community libraries: the concept and its application by the Pinetown Public Library. South African journal of library and information science 66(I): 10-22.

Public and community libraries directory. 2002. Pretoria: National Library of South Africa.

Ramogale, L. \& Fortuin, L.H. 2004. Transformation and equity in library and information services: a Gauteng case study. In: Bothma, T.J.D. \& Kaniki, A. 2004. Prolissa 2004. Proceedings of the 3rd biennial Dissanet conference, Pretoria, 28-29 October 2004. Pretoria: Infuse, pp 25I-266. (Also available online at $h$ ttp://www.dissanet.com.)

Roux, P.J.A., Weich, H.M. \& Fouché, B. 1986. Meaningful descriptive data for South African public libraries. South African journal of library and information science 54(2):45-55.

Snyman, M.E. \& Snyman, M.M.M. 2003. Getting information to disadvantaged rural communities: the centre approach. South African journal of libraries and information science 69(2):95-107.

Stillwell, C. 1994. Towards transformation? An update on the resource centres of South Africa. International information and library review 26:303-313.

Stillwell, C. 1997. Democracy and its emergence in South African public librarianship, or why public libraries plus a change of name don't equal community libraries. Innovation: appropriate librarianship and information work in South Africa (I5): 17-29.

Valentine, S. 2004. E-powering the people: South Africa's Smart Cape access project. Washingtom, DC: Council on Library and Information Resources. [Online]. Available http://www.clir.org/pubs/reports/pub/25/pub/25.pdf. Accessed 2 May 2005.

Van Helden, P. \& Lor, P.J. 200I. PaCLISA. Public and community library inventory of South Africa. [Online]. Available: http:// www.n/sa.ac.za/paclisa/index.htm. Accessed 16 May 2005.

Van Helden, P. \& Lor, P. J. 2002a. Public and community libraries inventory of South Africa, PaCLISA: final report. Pretoria: National Library of South Africa.

Van Helden, P. \& Lor, P.j. 2002b. The Public and Community Libraries Inventory of South Africa (PaCLISA) Project. (Version I). PaCLISA database. [CD-Rom]. Pretoria: National library of South Africa.

Wehmeyer, S. 1995. Public libraries update. Cape librarian 39(1):18-19.

Wehmeyer, S. 1996. Public libraries update RSA. Cape librarian 39(I): II. 
town or suburb level. This problem also resulted in the elimination of the public library depots from the GIS database. These could be located in retirement homes, nursery schools, military bases or prisons, some of which may be at some distance from the relevant town centre and were difficult or impossible to plot with any precision.

The project did not collect demographic data. Such data was purchased from the Statistics SA and the Municipal Demarcation Board. Essentially the PaCLISA GIS provided an overlay of library locations that could be superimposed on maps showing the distribution of demographic variables such as population density, mean household income, unemployment rate, number of children under 15 years, and educational level. As an example of the analyses that can be carried out using the GIS facility, Figure I plots the location of public libraries in the various wards of the Tshwane (formerly Greater Pretoria) Metropolitan area in Gauteng Province.

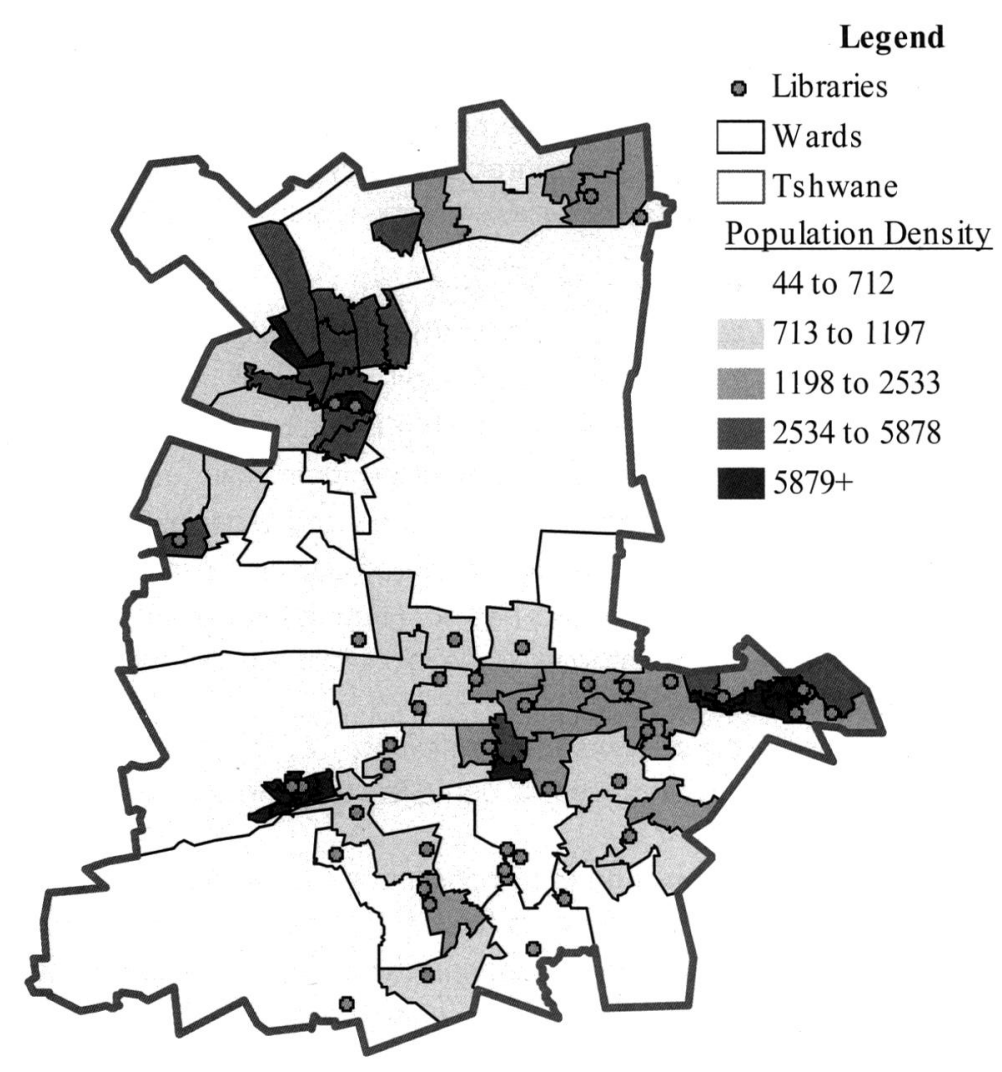

Figure 1 Libraries related to population density in the Tshwane metropolitan area

The wards with the darkest shading are the most densely populated; those with lightest shading have the lowest population density. The map shows that the densely populated "township" and "informal settlement" areas around the formerly "white" city of Pretoria to the north-west (Soshanguve, Mabopane, Winterveld, etc.), west (Atteridgeville) and east (Mamelodi) together have ten public library branches, whereas the affluent, sparsely populated suburbs of Centurion, a historically white area south of the city have as many or more branches serving a much smaller population. Using the GIS it is possible to zoom in for much greater detail, or to zoom out to maps covering much larger areas, such as the province of Gauteng or South Africa as a whole. Such maps can be used to map disparities and imbalances in public library provision, relating the latter not only to population density but also to other variables indicative of need, e.g. unemployment, income and literacy levels.

The descriptive data provided by the libraries that did return completed inventory questionnaires was input into the MS Access database. In view of the unsatisfactory response rate, a special attempt was made to obtain at least basic identification and location data from all the libraries. These libraries were contacted by fax and telephonically and were asked to provide only very basic descriptive data: size of collection and number of registered borrowers. As the checking and inputting of the descriptive data got under way, it became clear that in many cases the data was fragmentary or suspect. It is clear that South African public and community libraries do not collect statistical data on their assets and operations in a uniform manner. This appears to be because the managers of these libraries do not view effective 
management information as a priority. This attitude trickles down to the managers of local libraries and branches. As a result many libraries were not able to answer various questions in the questionnaire, and the accuracy of the data provided was also drawn into doubt. One of the categories in which data was least satisfactory was that of public library expenditure on print and other library materials. This was most disappointing as this information was of particular interest to the PICC. Given South Africa's multilingual population it was also very disappointing that so few libraries were able to provide an indication of their holdings of library materials in languages other than English and Afrikaans.

After a great deal of faxed and telephonic prompting and personal follow-up in order to fill in the gaps in the database, data entry was terminated and the following products were derived from the GIS and descriptive databases:

- A printed report (Van Helden \& Lor, 2002a)

- A website containing the report, the descriptive data, and a simple GIS system called the "library locator", that could be used to find the public and community libraries in a particular province, region or city (Van Helden \& Lor, 200I).

- A CD-ROM with the same contents as the website, but with a more limited search capability (Van Helden \& Lor, 2002b).

- A printed directory of the South Africa's public and community libraries (Public and community libraries directory, 2002). It had not originally been planned to produce a printed directory, but this was done at the request of public and community librarians who argued that many libraries still lack access to PCs and the Internet.

\section{Redesign of the inventory questionnaire}

Phase I provided the groundwork for an information system on public/community libraries that can be updated and utilised on an ongoing basis. Thus a second phase was planned to update and refine the original system. First, a new questionnaire was developed in order to make it easier for the participating public and community libraries to provide more accurate and complete answers. During Phase I, many respondents had found the questionnaire difficult to answer. Judging by the errors and omissions in the returned questionnaires, and especially by the explanatory notes and unasked for data and details that respondents had added to their completed questionnaires, there were various reasons for this:

- Some questions required data that the respondents had not routinely collected and that they could not readily provide on request (for example, in-house use of materials as distinct from borrowing).

- Some questions were found to be ambiguous.

- Some questions did not appear to respondents to be relevant.

- Some questions gave rise to anxiety because respondents felt that the answers could lead to misleading findings or place them in a bad light.

- Generally, the questionnaire was too long and time-consuming to complete.

Clearly, in order to actually gain valuable and useful data from the libraries, the questionnaire had to be adapted. There were two main thrusts: to reduce the number of questions and the amount of data requested; and to reduce ambiguity by providing a glossary and notes on the completion of the questionnaire. This process was undertaken by means of workshops with representatives of most of the country's public and community library authorities. The workshops were funded by the Carnegie Corporation of New York. Through this approach it was hoped that not only would a better questionnaire emerge, but that the joint decision-making process would lead to more "buy-in" and a higher response rate. The process of designing a new questionnaire is described in De Jager and Nassimbeni (2005). They elaborate on the process of arriving at a joint understanding of the aims and objectives of measuring performance in the South African public library system. With regards to the PaCLISA project, they conclude that this type of research is only the beginning of a "culture of assessment" (De Jager \& Nassimbeni, 2005:43) and suggest that a more complete picture is required.

\section{Phase 2}

Phase 2, which commenced in 2003, set out to provide such a more complete and up-to-date picture. After the questionnaire had been circulated among the PMC and PRG members for comment, it was pilot tested by a number of PMC members. Once approved, the new questionnaire was distributed to all the public/community libraries (with the help of various provincial and city library services). As in Phase I, in some cases the returned questionnaires were checked by the provincial authority before they were returned. The database was redesigned to effectively accommodate the different format of answers as requested by the new questionnaire. Again, the relevant geographic and demographic data was acquired from various sources and compiled into a number of basic layers for orientation and analysis purposes. The geographic data was used to map the individual libraries and determining the population they served. The data received from the returned questionnaires was coded and captured in the database.

Unfortunately, in Phase 2 problems were again experienced regarding the answering of the questionnaire. As in Phase I, the response rates in a number of provinces and metropolitan municipalities (metros) were very low. In a few provinces and metros the library authorities declined participation in the data collection exercise, citing workload, local government reorganisation, and in one case, the fact that the authority had undertaken its own survey. In some other 